\title{
A case series on simultaneous liver and kidney transplantation: do we need intraoperative renal replacement therapy?
}

\author{
Wongook Wi, Tae Soo Hahm, and Gaab-Soo Kim \\ Department of Anesthesiology and Pain Medicine, Samsung Medical Center, Seoul, Korea
}

Since the implementation of the model for end-stage liver disease (MELD) scoring system in 2002, the liver transplantation (LT) society has observed a substantial increase in the number of recipients with renal dysfunction. Intraoperative renal replacement therapy (ioRRT) has emerged as one of the solutions available to manage high-MELD score recipients; however, its usefulness has not yet been proven. To date, we have experienced five cases of simultaneous liver and kidney transplantation (SLKT). Recipients of SLKT tend to have a lower pre-transplant kidney function and the longer operation time mandates a larger amount of fluid than LT alone. Hence, anesthetic care is more prone to be challenged by hyperkalemia, metabolic acidosis, and volume overload, making ioRRT a theoretically valuable intervention. However, in all five cases, recipients were managed without ioRRT, resulting in excellent graft and patient survival. As such, in this case series, we discuss current issues about ioRRT and SLKT.

Key Words: Acidosis, Hyperkalemia, Liver transplantation, Renal replacement therapy.

In the United States (US), since the implementation of the model for end-stage liver disease (MELD) scoring system in 2002 , there has been a substantial increase in the number of liver transplantation (LT) candidates simultaneously suffering from renal dysfunction [1]. To deal with these high-MELD score recipients with pre-transplant renal dysfunction, some transplantation centers in the US have started to incorporate intraoperative renal replacement therapy (ioRRT). Unfortunately,

Corresponding author: Gaab-Soo Kim, M.D., Ph.D.

Department of Anesthesiology and Pain Medicine, Samsung Medical Center, 81, Ilwon-ro, Gangnam-gu, Seoul 06351, Korea

Tel: 82-2-3410-0360, Fax: 82-2-3410-0361

Email: gskim@skku.edu

ORCID: https://orcid.org/0000-0002-9383-2652

Received: October 27, 2016.

Revised: February 6, 2017 (1st); February 20, 2017 (2nd).

Accepted: February 22, 2017.

Korean J Anesthesiol 2017 August 70(4): 467-476

https://doi.org/10.4097/kjae.2017.70.4.467 a significant amount of strong evidence validating the usefulness of ioRRT during LT is scarce. In Korea, LT candidate prioritization changed from the Child Turcotte Pugh scoring system to the MELD scoring system in June 2016. Accordingly, as it has been shown in the US, the number of LT recipients having pretransplant renal dysfunction will likely rapidly increase. Consequently, increasing cases of intraoperative complications, including hyperkalemia, metabolic acidosis, and volume overload are expected during LT. Additionally, decisions regarding the need for ioRRT will be addressed more frequently to anesthesiologists. As such, it seems to be a reasonable moment to retrospectively discuss our current state and to prepare for post-MELD era challenges.

Currently, our institutional strategy does not include the performance of ioRRT due to its lack of supporting evidence. We have managed over 1,700 cases of LT without ioRRT to date. Although there is a strong expectation that ioRRT would be beneficial for recipients with pre-transplant renal dysfunction, there is little evidence supporting the decision to accept ioRRT as a routine practice. Theoretically, simultaneous liver and kid-

(c) This is an open-access article distributed under the terms of the Creative Commons Attribution Non-Commercial License (http://creativecommons.org/ licenses/by-nc/4.0/), which permits unrestricted non-commercial use, distribution, and reproduction in any medium, provided the original work is properly cited. 
ney transplantation (SLKT) recipients are more suitable candidates for ioRRT than those undergoing LT alone, as recipients of SLKT have irreversible kidney disease that is not expected to improve following LT without the assistance of a kidney transplant (KT) procedure. In addition, patients undergoing SLKT experience a longer operation time and require a larger amount of fluids. Therefore, we felt it was beneficial to gather relevant SLKT cases and analyze them with respect to the inclusion of intraoperative renal dysfunction management. Discussions on ioRRT and SLKT will follow.

\section{Case Report}

Five cases of SLKT have been performed in our institute since our first LT procedure in 1996. Four recipients had endstage liver disease due to hepatitis B virus, and one recipient had cryptogenic liver failure. Patients' MELD scores ranged from 21 to 23. Two recipients had hyponatremia preoperatively, and one recipient was managed in the intensive care unit (ICU) before the operation, but the patient did not require vasoactive drugs or ventilator therapy. None of the patients who underwent SLKT at our institute showed hepatorenal syndrome or encephalopathy prior to the operation.
In addition to liver disease, all of the five patients had renal dysfunction. Three had diabetic chronic kidney disease and one had membranoproliferative glomerulonephritis. The remaining one had unspecified glomerulonephritis and received $\mathrm{KT}$ in 2005, though the transplanted kidney became dysfunctional when he was hospitalized for the SLKT. All of the patients showed heterogeneity in kidney pathology, but none were expected to recover without a KT. Three of the patients had received preoperative renal replacement therapy (RRT), two via hemodialysis, and one via peritoneal dialysis. Kidney function assessed by serum creatinine (SCr)-based estimated glomerular filtration rate (eGFR) ranged from 3 to $46 \mathrm{ml} / \mathrm{min}$. All SCr values were obtained before RRT. These three recipients received preoperative RRT a day before the scheduled operation. Additional detailed information of the recipients is shown in Table 1.

\section{Operational procedures}

During the SLKT procedures, we focused on keeping not only adequate blood pressure without volume overload, but also homeostasis of the acid-base, electrolytes, and coagulation system. First, intravenous fluids comprised of both crystalloids and colloids were infused, targeting a mean arterial pressure over 70

Table 1. Demographic Features, Disease Severity, Preoperative Laboratory Results of SLKT Recipients

\begin{tabular}{|c|c|c|c|c|c|}
\hline ID & A & B & $\mathrm{C}$ & $\mathrm{D}$ & $\mathrm{E}$ \\
\hline \multicolumn{6}{|l|}{ General } \\
\hline Op. year/case number & $2015 / 1654$ & $2012 / 1265$ & $2009 / 825$ & $2008 / 732$ & $2002 / 199$ \\
\hline Gender/Age (yr) & Female/65 & Male/50 & Male/47 & Male/43 & Male/43 \\
\hline Height $(\mathrm{cm}) /$ Weight $(\mathrm{kg})$ & $146.5 / 65.1$ & $174.4 / 48.2$ & $162.3 / 50.9$ & $172.2 / 61$ & $175 / 86$ \\
\hline BMI $\left(\mathrm{kg} / \mathrm{m}^{2}\right)$ & 30.33 & 15.85 & 19.32 & 20.57 & 28.08 \\
\hline \multicolumn{6}{|l|}{ Disease Acuity } \\
\hline Cause of LC & Cryptogenic & Hepatitis B & Hepatitis B & Hepatitis B & Hepatitis B \\
\hline Cause of CKD & Diabetic & Congenital, KT & Diabetic & Diabetic & MPGN \\
\hline HTN/DM & $(+/+)$ & $(+/+)$ & $(+/+)$ & $(+/+)$ & $(+/-)$ \\
\hline Ascites/Splenomegaly & $(+/+)$ & $(+/+)$ & $(-/-)$ & $(-/-)$ & $(+/+)$ \\
\hline MELD score & 22 & 21 & 21 & 21 & 23 \\
\hline Pre-Op. RRT & Hemodialysis & $(-)$ & Hemodialysis & $(-)$ & PD \\
\hline Pre-Op. Day (Ward/ICU) & Ward (7) & Ward (6)/ICU (5) & Ward (3) & Ward (3) & Ward (2) \\
\hline \multicolumn{6}{|l|}{ Pre-Op. Laboratory results } \\
\hline Sodium/Potassium (mEq/L) & $137 / 4.4$ & $124 / 3.7$ & $142 / 5.3$ & $138 / 5.3$ & $129 / 3.6$ \\
\hline $\mathrm{SCr}(\mathrm{mg} / \mathrm{dl}) / \mathrm{eGFR}(\mathrm{ml} / \mathrm{min})$ & $2.31 / 21.2$ & $1.58 / 46.7$ & $6.43 / 10.3$ & $3.53 / 14.6$ & $17.6 / 3$ \\
\hline AST/ALT (IU/L) & $19 / 9$ & $20 / 12$ & $38 / 23$ & $339 / 263$ & $41 / 29$ \\
\hline PT INR/aPTT (s) & $1.24 / 45.2$ & $1.89 / 45.9$ & $1.16 / 37.2$ & $1.20 / 40.9$ & $1.3 / 43.5$ \\
\hline Total Bilirubin (mg/dl) & 0.4 & 2.4 & 0.5 & 0.6 & 0.6 \\
\hline Albumin (g/dl) & 3.5 & 3.6 & 3.8 & 1.8 & 3.8 \\
\hline LT donor/KT donor & Living/Living & Deceas/Deceas & Living/Living & Living/Living & Deceas/Living \\
\hline
\end{tabular}

SLKT: simultaneous liver and kidney transplantation, Op: operation, BMI: body mass index, LC: liver cirrhosis, CKD: chronic kidney disease, MPGN: membranoproliferative glomerulonephritis, KT: kidney transplantation, HTN: hypertension, DM: diabetes, MELD: model for end-stage liver disease, RRT: renal replacement therapy, PD: peritoneal dialysis, ICU: intensive care unit, SCr: serum creatinine, eGFR: estimated gulomerular filtration rate, AST: aspartate aminotransaminase, ALT: alanine aminotransaminase, PT INR: international normalized ratio of prothrombin time, aPTT: activated partial thromboplastin time, Deceas: deceased. 
mmHg. In cases $\mathrm{C}$ and D, 0.9\% saline was mainly infused while in case A, plasma solution A was mainly infused, as we changed maintenance fluid during LT from $0.9 \%$ saline to Plasma solution A (CJ Healthcare, Seoul, Korea). In cases B and E, the recipients had hyponatremia $(124 \mathrm{mEq} / \mathrm{L}$ and $129 \mathrm{mEq} / \mathrm{L}$, respectively) and so, $0.45 \%$ saline was the main fluid administered during the operations to prevent central pontine myelinolysis [2]. A continuous infusion of dopamine, norepinephrine, and vasopressin was also an effective option to maintain the target blood pressure. A large caliber central line (AVA, Edwards, Irvine, CA, USA) and pulmonary arterial catheter (Swan Ganz $\mathrm{SvO}_{2}$, Edwards, Irvine, CA, USA), with the aid of a corresponding monitoring system (Vigilance II, Edwards, Irvine, CA, USA), were utilized to choose the appropriate fluid and drug infusion rate.

Second, any imbalances of acid-base and electrolytes were monitored and corrected immediately. We performed arterial blood gas analysis from the start of operation and once every hour. A complete blood cell count, determination of international normalized ratio of prothrombin time (PT INR), activated partial thromboplastin time, fibrinogen, and thromboelastography were performed every two hours. At the start of both the anhepatic and the reperfusion phases, we set the clock to zero and recounted the time. Additional blood samples were collected at 10 minutes pre-reperfusion, and 5 and 30 minutes post-reperfusion. Ionized calcium values, below $0.8 \mathrm{mmol} / \mathrm{L}$, were handled with $300 \mathrm{mg}$ of calcium chloride. Potassium values over $4.5 \mathrm{mEq} / \mathrm{L}$ in pre-reperfusion period were handled with 10 international units (IU) or 5 IUs of regular insulin (RI) boluses, followed by a $5 \%$ dextrose solution infusion. To deal with metabolic acidosis, we infused 1 liter of $0.45 \%$ saline containing 80 $\mathrm{mEq}$ of sodium bicarbonate in cases in which base excess (BE) was below $-10 \mathrm{mmol} / \mathrm{L}$. However, in the first case (case E), we used a lower $\mathrm{BE}$ value to initiate bicarbonate infusion than that we use today [3].

Lastly, a strict rule was applied to every decision involving blood product transfusion. In total, $300 \mathrm{ml}$ of Cell Saver ${ }^{\circledR}$ (Haemonetics, Braintree, MA, USA) blood was infused in cases in which hemoglobin $(\mathrm{Hb})$ was below $9 \mathrm{~g} / \mathrm{dl}$, and two units of leukocyte-depleted red blood cells (LDRBC) were infused in cases in which $\mathrm{Hb}$ was below $8 \mathrm{~g} / \mathrm{dl}$. Additionally, we prepared two units of fresh frozen plasma (FFP) for when PT INR was above 3 and one unit of single-donor platelet for when platelet count was below 30,000/ $/$ l. Also, we infused six units of cryoprecipitates in cases in which fibrinogen was below $80 \mathrm{mg} / \mathrm{dl}$, but only three units of cryoprecipitates when platelet count was above 50,000 / $\mu \mathrm{l}$, even if the fibrinogen was below $80 \mathrm{mg} / \mathrm{dl}$. Operation time as well as total input and output are shown in Table 2. The most extreme results of the potassium and $\mathrm{BE}$ interventions we carried

Table 2. Input, Output, and Surgical Time during Operation

\begin{tabular}{|c|c|c|c|c|c|}
\hline ID & A & B & $\mathrm{C}$ & $\mathrm{D}$ & $\mathrm{E}$ \\
\hline \multicolumn{6}{|l|}{ Duration of operation time } \\
\hline Pre-Anhepatic phase & $05 \mathrm{~h} 13 \mathrm{~min}$ & $02 \mathrm{~h} 50 \mathrm{~min}$ & $03 \mathrm{~h} 15 \mathrm{~min}$ & $03 \mathrm{~h} 40 \mathrm{~min}$ & $04 \mathrm{~h} 36 \mathrm{~min}$ \\
\hline Anhepatic phase & $02 \mathrm{~h} 12 \mathrm{~min}$ & $02 \mathrm{~h} 51 \mathrm{~min}$ & $01 \mathrm{~h} 48 \mathrm{~min}$ & $01 \mathrm{~h} 45 \mathrm{~min}$ & $01 \mathrm{~h} 36 \mathrm{~min}$ \\
\hline Post-Reperfusion phase & $07 \mathrm{~h} 23 \mathrm{~min}$ & $11 \mathrm{~h} 30 \mathrm{~min}$ & $10 \mathrm{~h} 23 \mathrm{~min}$ & $08 \mathrm{~h} 27 \mathrm{~min}$ & $12 \mathrm{~h} 44 \mathrm{~min}$ \\
\hline Total & $14 \mathrm{~h} 58 \mathrm{~min}$ & $17 \mathrm{~h} 11 \mathrm{~min}$ & $15 \mathrm{~h} 26 \mathrm{~min}$ & $13 \mathrm{~h} 52 \mathrm{~min}$ & $18 \mathrm{~h} 56 \mathrm{~min}$ \\
\hline \multicolumn{6}{|l|}{ Input } \\
\hline Crystalloid (ml) & 17700 & 5100 & 6000 & 8000 & 5200 \\
\hline Half Saline (ml) & - & 13000 & 300 & 2000 & 6400 \\
\hline Colloid - Albumin 5\% (ml) & 2150 & 1080 & 250 & 91 & 500 \\
\hline Hextend 6\% (ml) & 1000 & 1000 & 1000 & 1000 & - \\
\hline Volulyte $6 \%(\mathrm{ml})$ & 500 & 1000 & - & - & - \\
\hline Pentastarch 10\% (ml) & - & - & - & - & 500 \\
\hline LDRBC (unit) & 2 & 9 & 1 & 2 & 10 \\
\hline FFP (unit) & 4 & 8 & - & - & 13 \\
\hline SDP (unit) & - & 2 & - & - & - \\
\hline Cryoprecipitate (unit) & 6 & 9 & - & - & - \\
\hline Cell Saver Blood (ml) & 1440 & 5730 & - & 450 & 1430 \\
\hline \multicolumn{6}{|l|}{ Output } \\
\hline Ascites (ml) & 2800 & 4000 & Negligible & Negligible & 250 \\
\hline UO - Before KT (ml) & 2140 & 740 & 450 & 550 & - \\
\hline Total $(\mathrm{ml})$ & 4870 & 1730 & 1300 & 680 & 900 \\
\hline EBL expressed as lost RCM (ml) & 1090 & 4493 & 187 & 363 & 2019 \\
\hline
\end{tabular}

LDRBC: leukocyte depleted red blood cell, FFP: fresh frozen plasma, SDP: single donor platelet, UO: urine output, EBL: estimated blood loss, RCM: red cell mass, RCM: red cell mass. EBL was expressed as lost RCM which is calculated as (real body weight) $\times 75(65$ in female $) \times($ preop HCT postop HCT) $/ 100+($ transfused LDRBC in unit $\times 213 \times 0.7)+($ transfused cell saver blood in $\mathrm{ml} \times 0.55)$. 
Table 3. Most Extreme Laboratory Findings and Interventions Carried Out

\begin{tabular}{|c|c|c|c|c|c|}
\hline ID & $\mathrm{A}$ & B & $\mathrm{C}$ & $\mathrm{D}$ & $\mathrm{E}$ \\
\hline Before LT Reperfusion & Anhep. $0 \mathrm{~h}$ & Anhep. $2 \mathrm{~h}$ & Anhep. $0 \mathrm{~h}$ & Op. $3 \mathrm{~h}$ & Anhep. $3 \mathrm{~h}$ \\
\hline Highest Potassium $(\mathrm{mEq} / \mathrm{L})$ & 4.6 & 3.4 & 4.5 & 4.5 & 4.3 \\
\hline RI bolus (IU) & 10 & - & 10 & 5 & - \\
\hline After LT Reperfusion & Reperf. $1 \mathrm{~h}$ & Reperf. $2 \mathrm{~h}$ & Reperf. $8 \mathrm{~h}$ & Reperf. $6 \mathrm{~h}$ & Reperf. $6 \mathrm{~h}$ \\
\hline Highest Potassium $(\mathrm{mEq} / \mathrm{L})$ & 3.7 & 3.8 & 4.6 & 4.9 & 5.4 \\
\hline RI bolus (IU) & - & - & - & - & 10 \\
\hline Before LT Reperfusion & Anhep. $0 \mathrm{~h}$ & Anhep. $2 \mathrm{~h}$ & Anhep. $1 \mathrm{~h}$ & Op. $2 \mathrm{~h}$ & Anhep. $1 \mathrm{~h}$ \\
\hline Lowest BE (mmol/L) & -7.4 & -9.3 & -3.7 & -11.0 & -16.1 \\
\hline $\mathrm{NaHCO}_{3}$ infusion $(\mathrm{mEq})$ & - & 60 & - & 80 & 50 \\
\hline After LT Reperfusion & Reperf. 5 min & Reperf. $4 \mathrm{~h}$ & Reperf. $4 \mathrm{~h}$ & Reperf. $7 \mathrm{~h}$ & Reperf. 5 min \\
\hline Lowest BE (mmol/L) & -8.9 & -14.6 & -9.7 & -15.5 & -17.3 \\
\hline $\mathrm{NaHCO}_{3}$ infusion $(\mathrm{mEq})$ & - & 420 & - & 80 & - \\
\hline
\end{tabular}

LT: liver transplantation, Anhep.: Anhepatic phase, Reperf.: Reperfusion phase, Op.: Operation start, RI: regular insulin, $\mathrm{BE}$ : base excess, $\mathrm{NaHCO}_{3}$ : sodium bicarbonate.

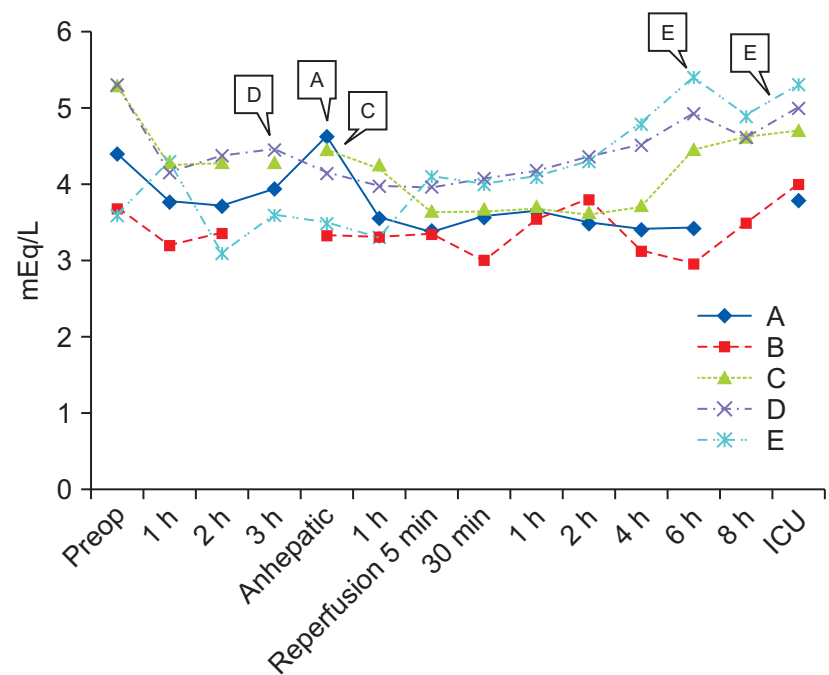

Fig. 1. Results of Potassium and Interventions Followed. In all cases, insulin bolus therapy was carried out to keep the potassium value under $4.5 \mathrm{mEq} / \mathrm{L}$ in pre-reperfusion period, and $5 \mathrm{mEq} / \mathrm{L}$ in post-reperfusion period. In case $\mathrm{A}, \mathrm{C}$, and $\mathrm{D}$, each needed one insulin bolus in prereperfusion period. In case E, two insulin boluses were needed in postreperfusion period. ICU: intensive care unit.

out are shown in Table 3. Figs. 1 and 2 are time series plots demonstrating the results of the laboratory tests and interventions.

\section{Hyperkalemia and metabolic acidosis}

In cases $\mathrm{A}, \mathrm{C}$, and $\mathrm{D}$, one RI bolus was needed in each prereperfusion period (because potassium values were $4.6 \mathrm{mEq} / \mathrm{L}$, $4.5 \mathrm{mEq} / \mathrm{L}$, and $4.5 \mathrm{mEq} / \mathrm{L}$, respectively). In case $\mathrm{E}$, RI bolus was not required in the pre-reperfusion period, but two RI boluses were given in the post-reperfusion period (because potassium values were $5.4 \mathrm{mEq} / \mathrm{L}$ and $5.1 \mathrm{mEq} / \mathrm{L}$, respectively). In case $\mathrm{B}$, RI bolus was not required at any point throughout the opera-

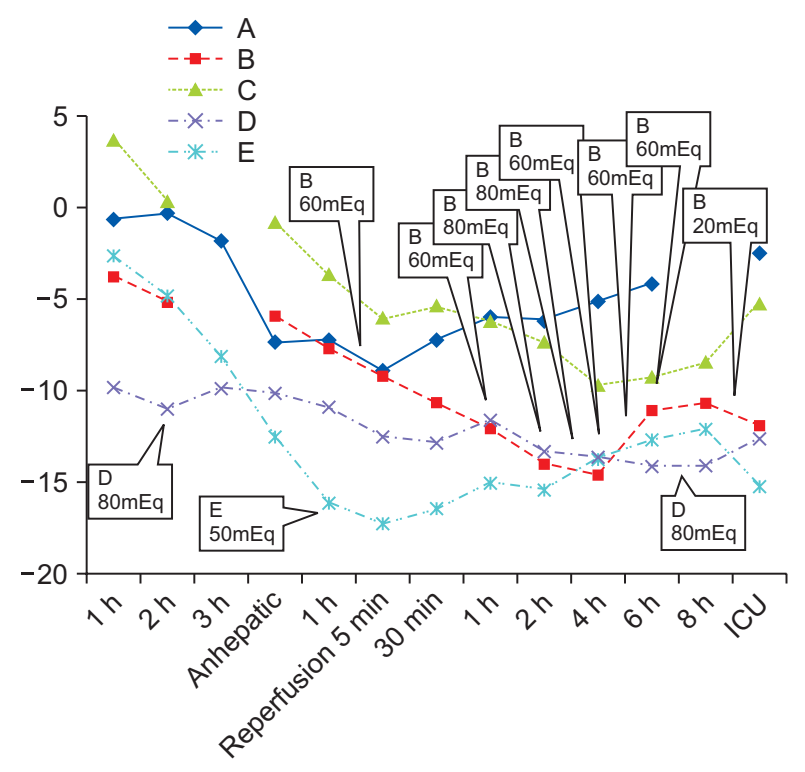

Fig. 2. Results of Base Excess and Interventions Followed. In case A, B, and $\mathrm{C}$, sodium bicarbonate was infused targeting base excess over -10 . In case $\mathrm{D}$ and $\mathrm{E}$, sodium bicarbonate was infused targeting base excess over -15 . ICU: intensive care unit.

tion.

In cases $\mathrm{A}$ and $\mathrm{C}, \mathrm{BE}$ values were kept above $-10 \mathrm{mmol} /$ $\mathrm{L}$, throughout the operation, and sodium bicarbonate infusion was not needed. In case $\mathrm{D}, 80 \mathrm{mEq}$ of sodium bicarbonate was infused in the pre-reperfusion period (BE value was -11.0 $\mathrm{mmol} / \mathrm{L}$ at two hours into the operation) and another $80 \mathrm{mEq}$ of sodium bicarbonate was infused in the post-reperfusion period (BE value was $-15.5 \mathrm{mmol} / \mathrm{L}$ at seven hours post-reperfusion). In case $\mathrm{E}, 50 \mathrm{mEq}$ of sodium bicarbonate was infused in the prereperfusion period (BE value was $-16.1 \mathrm{mmol} / \mathrm{L}$ at one hour into the anhepatic) but sodium bicarbonate was not followed even when the $\mathrm{BE}$ decreased to lower than $-15 \mathrm{mmol} / \mathrm{L}$ in the 
post-reperfusion period. On the contrary, in case B, vigorous efforts to keep the $\mathrm{BE}$ above $-10 \mathrm{mmol} / \mathrm{L}$ in both the pre- and post-reperfusion periods were carried out. A total amount of $480 \mathrm{mEq}$ of sodium bicarbonate was infused as a result. Ironically, this patient, who received the most aggressive sodium bicarbonate therapy, died a month after the operation. He was the only recipient who received both deceased liver and kidney grafts, and also the only one who received continuous renal replacement therapy (CRRT) after the operation. Our aggressive sodium bicarbonate infusion therapy worked effectively throughout the operation. However, inappropriate function of the deceased liver and kidney grafts, to our knowledge, initiated the fatal clinical outcome in the post-operative period.
Metabolic acidosis was managed tightly in four of the cases (in cases $\mathrm{A}, \mathrm{B}, \mathrm{C}$, and $\mathrm{D}$ ). In case $\mathrm{E}$, however, the $\mathrm{BE}$ value to initiate the infusion of sodium bicarbonate was lower than that we use today [3]. As a result, less aggressive sodium bicarbonate infusion therapy was conducted, and even a BE value below $-15 \mathrm{mmol} / \mathrm{L}$ was observed without intervention. However, as the kidney graft successfully functioned, the laboratory results all converged to normal after the operation, and hemodynamic instability remained unreported during the operation.

None of the five recipients showed signs or symptoms of volume overload in the post-operative period. Post-operative chest $\mathrm{X}$-rays revealed absence of pulmonary edema and/or pleural effusion in all cases. The $\mathrm{PaO}_{2} / \mathrm{FIO}_{2}$ value before extubation at

Table 4. Laboratory Results during Operation

\begin{tabular}{|c|c|c|c|c|c|}
\hline ID & A & B & $\mathrm{C}$ & $\mathrm{D}$ & $\mathrm{E}$ \\
\hline \multicolumn{6}{|l|}{$\mathrm{pH}$} \\
\hline Pre-anhepatic & $7.30-7.43$ & $7.42-7.35$ & $7.42-7.54$ & $7.27-7.32$ & $7.27-7.46$ \\
\hline Anhepatic & $7.32-7.35$ & $7.26-7.35$ & 7.39 & 7.21 & $7.17-7.20$ \\
\hline Reperfusion & 7.29 & 7.23 & 7.28 & 7.20 & 7.13 \\
\hline Post-liver & $7.29-7.35$ & $7.14-7.28$ & $7.24-7.33$ & $7.16-7.21$ & $7.12-7.24$ \\
\hline Post-kidney & $7.28-7.36$ & $7.28-7.29$ & $7.30-7.31$ & $7.13-7.24$ & 7.26 \\
\hline \multicolumn{6}{|l|}{$\mathrm{Na}(\mathrm{mEq} / \mathrm{L})$} \\
\hline Pre-anhepatic & $133.2-133.5$ & $121.1-121.2$ & $131.9-132.8$ & $131.9-132.8$ & $128-136$ \\
\hline Anhepatic & $131.1-132.2$ & $121.0-123.2$ & 132.8 & 133.0 & $135-137$ \\
\hline Reperfusion & 131.7 & 122.7 & 132.9 & 133.8 & 126 \\
\hline Post-liver & $132.1-135.4$ & $122.9-127.6$ & $133.0-135.5$ & $133.1-136.2$ & $130-135$ \\
\hline Post-kidney & $130.5-136.1$ & $122.1-135$ & $129.0-129.9$ & $131.9-135.4$ & $130-131$ \\
\hline \multicolumn{6}{|l|}{ Lactate $(\mathrm{mmol} / \mathrm{L})$} \\
\hline Pre-anhepatic & $0.78-1.43$ & $1.14-1.57$ & $1.21-2.23$ & $1.35-1.79$ & - \\
\hline Anhepatic & $2.89-3.39$ & $1.87-4.72$ & 3.85 & 2.25 & - \\
\hline Reperfusion & 4.23 & 5.78 & 4.93 & 2.28 & - \\
\hline Post-liver & $2.87-3.60$ & $5.59-9.08$ & $4.88-7.35$ & $1.17-1.75$ & - \\
\hline Post-kidney & $2.97-3.18$ & $7.66-7.84$ & $3.27-3.97$ & $0.60-1.05$ & - \\
\hline \multicolumn{6}{|l|}{$\operatorname{PLT}(1000 / \mu \mathrm{l})$} \\
\hline Pre-anhepatic & $79-87$ & 22 & $88-104$ & $66-71$ & $36-67$ \\
\hline Anhepatic & $48-66$ & $26-38$ & 79 & 47 & 54 \\
\hline Reperfusion & 56 & 42 & 83 & 47 & 69 \\
\hline Post-liver & $51-66$ & $12-98$ & $88-111$ & $51-56$ & $58-70$ \\
\hline Post-kidney & 73 & 60 & 94 & $50-61$ & 57 \\
\hline \multicolumn{6}{|l|}{ PT INR } \\
\hline Pre-anhepatic & $1.44-1.69$ & 2.02 & $1.09-1.19$ & 1.32 & $1.33-1.34$ \\
\hline Anhepatic & $2.68-3.71$ & $2.38-3.06$ & 1.17 & 1.60 & 1.59 \\
\hline Reperfusion & 2.79 & 3.81 & 1.34 & 1.79 & 2.84 \\
\hline Post-liver & $2.45-3.66$ & $4.42-11.89$ & $1.35-1.57$ & $1.78-1.99$ & $1.62-3.22$ \\
\hline Post-kidney & 2.68 & 4.24 & 1.58 & $2.07-2.23$ & 3.01 \\
\hline \multicolumn{6}{|l|}{$\operatorname{aPTT}(\mathrm{s})$} \\
\hline Pre-anhepatic & $44.8-48.5$ & 48.5 & $32.7-37.6$ & $42.4-43.5$ & $40.7-121.5$ \\
\hline Anhepatic & $71.9-113.6$ & $55.6-70.4$ & 32.8 & 51.9 & 39 \\
\hline Reperfusion & 87 & 202.7 & 38.2 & 66.5 & 66.2 \\
\hline Post-liver & $97.7-112.7$ & $168.5-300$ & $39.0-43.2$ & $58.2-60.2$ & $48.1-89.0$ \\
\hline Post-kidney & 105.1 & 160.6 & 43.9 & $59.2-65.2$ & 64.4 \\
\hline
\end{tabular}

PLT: platelet count, PT INR: international normalized ratio of prothrombin time, aPTT: activated partial thromboplastin time. 
Table 5. Laboratory Results at ICU

\begin{tabular}{|c|c|c|c|c|c|}
\hline ID & $\mathrm{A}$ & B & $\mathrm{C}$ & $\mathrm{D}$ & $\mathrm{E}$ \\
\hline \multicolumn{6}{|l|}{ AST/ALT (IU/L) } \\
\hline 1st at ICU & $586 / 424$ & $2767 / 1947$ & $161 / 119$ & $324 / 370$ & $6810 / 3452$ \\
\hline 1 Day & $346 / 429$ & $1519 / 676$ & $195 / 179$ & $252 / 289$ & $2261 / 1868$ \\
\hline 1 Week & $40 / 176$ & $65 / 290$ & $22 / 79$ & $27 / 68$ & $40 / 147$ \\
\hline 1 Month & $21 / 153$ & - & $24 / 28$ & $423 / 41$ & $28 / 37$ \\
\hline \multicolumn{6}{|c|}{$\mathrm{SCr}(\mathrm{mg} / \mathrm{dl}) / \mathrm{eGFR}(\mathrm{mmol} / \mathrm{L})$} \\
\hline 1 st at ICU & $1.01 / 55$ & $1.00 / 79.1$ & $4.04 / 16.2$ & $3.02 / 17.3$ & $12.4 / 5$ \\
\hline 1 Day & $0.48 / 129.8$ & $1.43 / 52.3$ & $1.49 / 54$ & $2.12 / 36$ & $3.4 / 21$ \\
\hline 1 Week & $0.71 / 82.6$ & $3.96 / 16.2$ & $0.85 / 103$ & $1.07 / 61$ & $1.5 / 54$ \\
\hline 1 Month & $1.12 / 48.8$ & - & $1.02 / 79.7$ & $1.39 / 50.6$ & $1.0 / 87$ \\
\hline \multicolumn{6}{|l|}{ Potassium (mEq/L) } \\
\hline 1 st at ICU & 3.8 & 4.0 & 4.7 & 5.0 & 5.3 \\
\hline 1 Day & 4.3 & 4.1 & 4.3 & 3.7 & 3.8 \\
\hline 1 Week & 5.8 & 5.2 & 4.8 & 4.2 & 4.3 \\
\hline 1 Month & 5.2 & - & 4.0 & 5.7 & 4.5 \\
\hline \multicolumn{6}{|l|}{ PT INR / aPTT (s) } \\
\hline 1st at ICU & $2.61 / 67.6$ & $3.41 / 89.0$ & $1.48 / 41.1$ & $1.96 / 57.8$ & $2.58 / 62.1$ \\
\hline 1 Day & $2.16 / 78.1$ & $1.81 / 52.8$ & $1.50 / 41.3$ & $2.34 / 64.1$ & $2.99 / 69.1$ \\
\hline 1 Week & $1.11 / 35.3$ & $1.97 / 51.9$ & $1.09 / 28.3$ & $1.52 / 41.9$ & $1.09 / 34.2$ \\
\hline 1 Month & $1.40 / 42.8$ & - & $1.01 / 27.8$ & $1.18 / 31.2$ & $1.09 / 34.8$ \\
\hline
\end{tabular}

ICU: intensive care unit, AST: aspartate aminotransaminase, ALT: alanine aminotransaminase, SCr: serum creatinine, EGFR: estimated glomerular filtration rate, PT INR: international normalized ratio of prothrombin time, aPTT: activated partial thromboplastin time.

Table 6. LOS and Survival

\begin{tabular}{lccccc}
\hline \multicolumn{1}{c}{ ID } & A & B & C & D & E \\
\hline LOS (days) & & & 7 & 6 & 22 \\
ICU & 8 & 27 & 13 & $\mathrm{O}$ & $\mathrm{O} / \mathrm{O} / \mathrm{O}$ \\
Ward & 13 & - & $\mathrm{O} / \mathrm{O} / \mathrm{O}$ & $\mathrm{O} / \mathrm{O} / \mathrm{O}$ & $\mathrm{O} / \mathrm{O} / \mathrm{O}$ \\
Survival (Patient/Liver/ Kidney) & & $\mathrm{O} / \mathrm{O} / \mathrm{O}$ & $\mathrm{O} / \mathrm{O} / \mathrm{O}$ & $\mathrm{O} / \mathrm{O} / \mathrm{O}$ \\
1 Month & $\mathrm{O} / \mathrm{O} / \mathrm{O}$ & $\mathrm{O} / \mathrm{O} / \mathrm{O}$ & - & $\mathrm{O} / \mathrm{O} / \mathrm{O}$ & $\mathrm{O} / \mathrm{O} / \mathrm{O}$ \\
1 Year & - & - & - & $\mathrm{O} / \mathrm{O} / \mathrm{O}$ \\
3 Years & - & - & - & \\
5 Years & - & - & & \\
10 Years & & &
\end{tabular}

LOS: length of stay, ICU: intensive care unit.

ICU was 254 (A), 361 (B), 418 (C), 263 (D) and $256(\mathrm{E})$, respectively. Laboratory results other than potassium and $\mathrm{BE}$ during the operation are shown in Table 4, while laboratory results at ICU are shown in Table 5. Length of hospital stay, patients and grafts survival rates are shown in Table 6.

\section{Accumulation of wasted materials}

Even if potassium and metabolic acidosis were managed sufficiently without the use of ioRRT, it is unknown how much waste material is being accumulated during the operation. To identify it, in the most recent case (case A), we performed an additional laboratory test just before the reperfusion of the kidney graft. It took approximately 12 hours from the start of the operation to the reperfusion of the kidney graft. Blood urea nitrogen and SCr values before the operation were $17 \mathrm{mg} / \mathrm{dl}$ and $1.93 \mathrm{mg} /$ $\mathrm{dl}$ respectively, and they decreased to $11.7 \mathrm{mg} / \mathrm{dl}$ and $1.31 \mathrm{mg} / \mathrm{dl}$ just before the kidney reperfusion. Total input and output at that moment were $15,100 \mathrm{ml}$ of crystalloid, $1,670 \mathrm{ml}$ of $5 \%$ albumin, $1,000 \mathrm{ml}$ of $6 \%$ Hextend (CJ Healthcare, Seoul, Korea), $500 \mathrm{ml}$ of $6 \%$ Volulyte (Fresenius Kabi, Bad Homburg, Germany), 430 $\mathrm{ml}$ of $15 \%$ mannitol, $1,439 \mathrm{ml}$ of Cell Saver ${ }^{\circledR}$ blood, two units of LDRBC, four units of FFP, six units of cryoprecipitate, and 2,140 $\mathrm{ml}$ of urine output. Total estimated blood loss was 5,175 ml. We discussed the decrement of SCr during the operation and postulated that the decrement of body waste could be the result of the 
removal of a huge amount of body fluid via surgical bleeding. Meanwhile, supplementation of fluids and fresh blood products mimicked the function of ioRRT.

\section{Discussion}

In the Korean Journal of Anesthesiology, four case reports of SLKT were identified. In 2002, Lee et al. [4] reported a case of SLKT (living liver and kidney donor) in a 45-year-old man receiving preoperative hemodialysis. Authors discussed the case with transplant surgeons and decided not to use ioRRT because of its unfamiliarity. Instead, they decided to implant the kidney graft earlier and the liver graft later, to ease the intraoperative management of renal dysfunction. Liver grafting is usually implanted earlier than kidney grafting to avoid kidney graft hypoperfusion during the liver reperfusion period, and to shorten the ischemia time of liver grafting, which is known to be more more limited than that of the kidney grafting. However, the authors in that case concluded that in the living donor LT, ischemia time could be shortened by timing the operation of the donor to that of the recipient. The implanted kidney graft functioned well during whole operation, including in the liver reperfusion period, and anesthesia was maintained successfully.

In 2009, Park et al. [5] reported a case of SLKT (deceased liver and kidney donor) in a 13-year-old child receiving preoperative peritoneal dialysis. Authors found it difficult to place an additional large caliber central line in a child, and so did not use ioRRT. Instead, they used non-potassium-containing fluid, fresh blood products within a week and sodium bicarbonate infusion, which resulted in an adequate acid-base and electrolyte balance during the operation. Of interest in that case is the fact that the authors used non-potassium-containing 0.9\% saline during SLKT. Recent studies on balanced crystalloids have revealed the benefits of low incidence of hyperchloremic metabolic acidosis and renal vasoconstriction, implicating less kidney injury [6]. In addition, a more recent randomized controlled study reported that the risk of hyperkalemia in $\mathrm{KT}$ recipients receiving acetatebuffered balanced solution was not significantly higher than in $\mathrm{KT}$ recipients receiving $0.9 \%$ saline, although the former solution contains potassium [8]. Therefore, in light of this information, we changed our primary fluid during LT and KT from $0.9 \%$ saline to acetate-buffered balanced crystalloid (i.e., Plasma solution $\mathrm{A})$.

In 2002, Huh et al. [7] reported two cases of SLKT. One involved a deceased donor and the other involved a living donor. Authors used ioRRT in the living donor case, and a clot formation in the filter disabled the system two hours after initiation. They replaced the filter, and the system stopped again after another two hours. The last period of anesthesia was maintained well without ioRRT. Theoretically, ioRRT actually has several complications. Above all, ioRRT has a risk of filter clotting. Unfortunately, systemic anticoagulation has a risk of increased bleeding tendency. It is difficult to stay at an appropriate point between pro-coagulation and anti-coagulation in patients with end-stage liver disease because they already have a drifting balance of coagulation. Recently, a regional anticoagulation technique with circuit inborn citrate was invented as an alternative. Other reported complications of ioRRT include hypothermia, vascular access dysfunction, fluid and electrolyte balance errors and, rarely, mechanical problems. Financial issues should also not be ignored, because ioRRT has been reported to consume a significant portion of national medical insurance resources in Korea.

As a next step, we searched international reference databases and found a few studies on the use of ioRRT in LT and SLKT. In the early 2000s, there were sporadic case reports and experience reports prepared by a single center or authors with a small-sized study population, addressing the possibility of better intraoperative management of metabolic and acid-base homeostasis with ioRRT. In 2011, Parmar et al. [9] reported a retrospective cohort study of ioRRT in 72 LT recipients, and noted that there was no difference in post-operative complication rates between ioRRT and non-ioRRT groups, despite the fact that the ioRRT group had a higher pre-operative disease severity and CRRT ratio. However, this report was limited by the failure to incorporate matching between the two groups. In 2014, Agopian et al. [10] reported a retrospective cohort study of ioRRT in 407 LT and 93 SLKT recipients who were already receiving preoperative CRRT. Among them, 401 patients did not receive ioRRT, 70 patients received planned ioRRT, and 29 patients received emergent ioRRT. Perioperative variables were analyzed between these three groups, and the authors observed similar intraoperative complication rates between the planned-ioRRT group and nonioRRT group, despite the fact that preoperative disease severity variables were significantly worse in the planned-ioRRT group. From this, they suggested that these intraoperative outcomes, observed to be better than expected in the planned-ioRRT group, were in fact due to the utilization of ioRRT. In addition, they observed significantly lower intraoperative complication rates in the planned-ioRRT group than in the emergentioRRT group, despite the fact that preoperative disease severity variables were similar in the two groups. From this, the authors also suggested that the inferior intraoperative results in the emergent-ioRRT group could be due to not initiating ioRRT as a planned intervention.

As was demonstrated, most studies on the use of ioRRT are mainly observational or retrospective, and the necessary strong evidence does not exist so far. Fortunately, according to clinicaltrials.gov, the first large multicenter, prospective randomized controlled trial is in process by Bagshaw et al., which began in 
2012. This study is designed to compare ioRRT during LT with standard supportive therapy in patients with a glomerular filtration rate (GFR) of less than $60 \mathrm{ml} / \mathrm{min}$. The results are preliminary and the study population is limited to non-pre-transplant CRRT patients receiving LT alone; nevertheless, the study may become a cornerstone for ioRRT research and may affect the future management of high-MELD score recipients in the future.

\section{Simultaneous liver and kidney transplantation}

As a last step in this study, we searched literature databases for SLKT listing criteria. We realized that almost all of the SLKT recipients in Korea, including the patients from our cases, showed lower MELD scores as compared with recipients in the US. In living donor SLKT, the availability of simultaneous donors exerts more leverage on the decision of SLKT than the nature of the disease itself. However, even in the deceased donor case (case B), kidney function was enough to filtrate body wastes without RRT (SCr $1.58 \mathrm{mg} / \mathrm{dl}$ ). This may be attributed to the current non-existence of SLKT listing criteria in Korea. In the US, there are a few consensus guidelines on SLKT listing criteria, which have been largely made and revised using Organ Procurement and Transplantation Network (OPTN) data. However, they are, by all means, not perfect and there are still many obstacles to be solved.

First, currently there is no consensus on the definitions of AKI and chronic kidney disease (CKD) in the setting of LT. It is well known that SCr, the classic biomarker, can lead to overestimation of the true kidney function in end-stage liver disease recipients. However, the feasibility and widespread laboratory availability of SCr has made it to form the basis for estimating the degree of renal dysfunction, even in LT and SLKT. For now, the most notable definition of renal dysfunction is the Risk, Injury, Failure, Loss, End-stage kidney disease (RIFLE) 5 stage criteria developed in 2004, which was modified to a three-stage system by the Acute Kidney Injury Network (AKIN) in 2007. Kidney Disease: Improving Global Outcomes (KDIGO) in 2012 added a last touch to the RIFLE criteria by formulating albuminuria criteria and applying a time frame to the SCr criteria. Furthermore, to define renal dysfunction in LT recipients, a working party by the Acute Dialysis Quality Initiative (ADQI) and International Ascites Club in 2011 suggested a proposal to apply the RIFLE criteria to define AKI and CKD in patients with cirrhosis, irrespective of the cause [11]. New candidates for biomarkers, such as cystatin $\mathrm{C}$ and neutrophil gelatinase-associated lipocalin (NGAL), are currently under investigation. A new definition of renal dysfunction made up by those novel biomarkers is needed to create an appropriate SLKT listing criteria.

Second, key factors that determine non-recovery of kidney function after LT remain poorly defined. Recently, Sharma et al.
[12] reported a retrospective review analyzing 2,112 adult deceased donor LT recipients who received acute RRT for less than 90 days before LT. The authors concluded that native renal function was recovered in the majority of patients within six months post-transplant, with the cumulative risk of renal non-recovery being $8.9 \%$. According to the study by Sharma et al., risk factors of renal non-recovery were age at LT, longer duration of RRT, retransplant and pre-LT diabetes. Although it is a good option for a patient who has both end-stage liver and kidney disease, SLKT should not be performed in patients in whom renal dysfunction is expected to disappear after LT. According to literatures, in the past decade in the US, more than 30,000 adults were added to the KT waiting list annually, but only 55-60\% eventually received a deceased kidney graft. During that same time period, $13-15 \%$ of the individuals on the waiting list died while waiting for a transplant and $3-10 \%$ of them were removed from the list due to high disease severity. It should be noted that organ shortage is apparent in Korea, too. Further research on eligible risk factors is needed to avoid overzealous listing for SLKT.

Third, the appropriate time to initiate RRT in recipients waiting for SLKT is unknown. In the first national survey of practice patterns of SLKT in the US by OPTN, 70\% of centers used dialysis duration as a criterion to determine the need for SLKT, whereas $30 \%$ of centers used AKI duration [1]. However, there is still no guideline regarding when to start RRT in recipients waiting on a list. The decision of when to begin RRT is especially difficult to make in cases in which recipients develop AKI. Thus, a consensus on this decision is essential to build an acting SLKT criteria that embodies all recipients with or without RRT.

Lastly, there are debates regarding the true benefits of SLKT. In a review based on OPTN data by Formica et al. [13], recipients undergoing LT with $\mathrm{SCr}>2.5 \mathrm{mg} / \mathrm{dl}$ or pre-transplant dialysis time of $>2$ months have $81.1 \%$ one-year survival rate and $65.9 \%$ five-year survival rate. SLKT increased this outcome to only $86.2 \%$ and $70.1 \%$, respectively. More recent study data based on a propensity score-analysis of OPTN data concluded that survival benefit may even be as little as one month at five years after transplantation [14]. In addition, transplantation of a kidney graft in recipients of LT with a high risk of mortality can be a waste of scarce organs. In a single-center study consisting of 169 patients with a MELD score > 40, futile LT outcomes (defined as three-month mortality or in-hospital mortality) occurred in over $22 \%$ of those involved in the study. In another analysis using the national database, patients with MELD score $>40$ were more than twice as likely to die within 30 days of transplant than those with MELD scores of less than 30. According to them, futility predictive factors included age $>60$ years, body mass index $>30 \mathrm{~kg} / \mathrm{m}^{2}$, a pre-transplant requirement for ICU care or life support and the presence of multiple comorbidities [15]. The overall one-year kidney graft survival after SLKT 
was $77.2 \%$, while graft survival after $\mathrm{KT}$ alone was $89.3 \%$, following OPTN data in a similar study. Thus, the additory benefit from SLKT over LT alone should be better estimated and balanced with the disadvantage of patients waiting for KT alone.

Despite all of the limitations above, several consensus guidelines for SLKT listing criteria were made and published by several researchers as well as associations and government divisions in the US. The most notable ones are those from two big consensus conferences by OPTN. The first one was published by Eason et al. in 2008 and the second one by Nadim et al. in 2012 [1]. The latter one adopted and modified the definition of $\mathrm{AKI}$ and CKD by KDIGO, and consisted of persistent AKI for more than four weeks, CKD for three months and metabolic diseases that affect both the liver and kidney. Recently, OPTN pronounced a new SLKT allocation criteria in 2016 [13]. Those criteria are as follows. Metabolic diseases requiring SLKT (for example, primary hyperoxaluria), sustained AKI (defined as eGFR $<25 \mathrm{ml} / \mathrm{min}$ for six consecutive weeks) and/or CKD (defined as eGFR $<60 \mathrm{ml} / \mathrm{min}$ for $>90$ days prior to listing and $<30 \mathrm{ml} / \mathrm{min}$ at the time of listing). All eGFR values are based on a six-variable Modified Diet in Renal Disease formula. The guideline in 2016 also incorporated the concept of a "safety net," which means prioritizing the patients who received LT to the kidney graft listing, in case of renal non-recovery. It was suggested that the addition of this component may affect the decision to undergo SLKT by removing the concern that if a patient does not receive the SLKT, that they will remain on dialysis and suffer a worse outcome.

In summary, we searched reported references to figure out the necessity of ioRRT in LT and SLKT. We also searched references to make an appropriate decision on the performance of SLKT, instead of LT alone. As we discussed above, great challenges are expected following the adoption of the MELD scoring system. It is not just a simple matter of increasing renal dysfunction; there are bundles of problems to be solved, like a domino effect. Utilization of novel biomarkers in LT recipients, the development of a more precise formula to detect kidney injury earlier; locating more risk factors on post-LT renal non-recovery; analyzing the effects of ioRRT on the renal recovery and determining the benefits of ioRRT in either living or deceased grafts; investigating complication reports of ioRRT; building a national statistics of SLKT and ioRRT; estimating the additory benefit from SLKT and the disadvantage of patients on KT waiting list; and finally, establishing our own consensus criteria for both ioRRT and SLKT are all important considerations in the postMELD era of LT anesthetic portion of care. Further research is needed indeed in next decade.

\section{ORCID}

Wongook Wi, https://orcid.org/0000-0001-8102-2620

Gaab-Soo Kim, https://orcid.org/0000-0002-9383-2652

\section{References}

1. Nadim MK, Sung RS, Davis CL, Andreoni KA, Biggins SW, Danovitch GM, et al. Simultaneous liver-kidney transplantation summit: current state and future directions. Am J Transplant 2012; 12: 2901-8.

2. Jeong HK, Gwak MS, Kim GS. Central pontine myelinolysis after liver transplantation: a case report. Korean J Anesthesiol 2006; 50: 469-73.

3. Lee YM, Gwak MS, Cho HS, Kim GS. Acid-base status without sodium bicarbonate administration during orthotopic liver transplantation. Korean J Anesthesiol 1999; 37: 631-6.

4. Lee JM, Kim TH, Choi JH. Anesthetic management of living related hepatorenal transplantation. Korean J Anesthesiol 2002; 42: 120-4.

5. Park JM, Lee KH, Jung CW. Anesthesia for synchronous liver and kidney transplantation in a child: A case report. Korean J Anesthesiol 2009; 57: 381-6.

6. Yunos NM, Bellomo R, Hegarty C, Story D, Ho L, Bailey M. Association between a chloride-liberal vs chloride-restrictive intravenous fluid administration strategy and kidney injury in critically ill adults. JAMA 2012; 308: 1566-72.

7. Huh IY, Cho IS, Hwang KS, Choi KT. Anesthesia for synchronous liver-kidney transplantation. Korean J Anesthesiol 2002; 42: 414-21.

8. Potura E, Lindner G, Biesenbach P, Funk GC, Reiterer C, Kabon B, et al. An acetate-buffered balanced crystalloid versus $0.9 \%$ saline in patients with end-stage renal disease undergoing cadaveric renal transplantation: a prospective randomized controlled trial. Anesth Analg 2015; 120: 123-9.

9. Parmar A, Bigam D, Meeberg G, Cave D, Townsend DR, Gibney RT, et al. An evaluation of intraoperative renal support during liver transplantation: a matched cohort study. Blood Purif 2011; 32: 238-48.

10. Agopian VG, Dhillon A, Baber J, Kaldas FM, Zarrinpar A, Farmer DG, et al. Liver transplantation in recipients receiving renal replacement therapy: outcomes analysis and the role of intraoperative hemodialysis. Am J Transplant 2014; 14: 1638-47.

11. Wong F, Nadim MK, Kellum JA, Salerno F, Bellomo R, Gerbes A, et al. Working Party proposal for a revised classification system of renal dysfunction in patients with cirrhosis. Gut 2011; 60: 702-9.

12. Sharma P, Goodrich NP, Zhang M, Guidinger MK, Schaubel DE, Merion RM. Short-term pretransplant renal replacement therapy and renal nonrecovery after liver transplantation alone. Clin J Am Soc Nephrol 2013; 8: 1135-42. 
13. Formica RN, Aeder M, Boyle G, Kucheryavaya A, Stewart D, Hirose R, et al. Simultaneous liver-kidney allocation policy: a proposal to optimize appropriate utilization of scarce resources. Am J Transplant 2016; 16: 758-66.

14. Sharma P, Shu X, Schaubel DE, Sung RS, Magee JC. Propensity score-based survival benefit of simultaneous liver-kidney transplant over liver transplant alone for recipients with pretransplant renal dysfunction. Liver Transpl 2016; 22: 71-9.

15. Panchal HJ, Durinka JB, Patterson J, Karipineni F, Ashburn S, Siskind E, et al. Survival outcomes in liver transplant recipients with Model for End-stage Liver Disease scores of 40 or higher: a decade-long experience. HPB (Oxford) 2015; 17: 1074-84. 